CERN

\section{How to pay British share}

BRITISH Foreign Office subscriptions to international bodies are effectively protected against exchange rate fluctuations by the Treasury - so why should not the international subscriptions of the Science and Engineering Council (SERC) be similarly protected? Two Oxford high-energy physicists, Professor Don Perkins and Dr John Mulvey, have put this question to their local Member of Parliament, Tory John Patten, who has promised to raise the matter with Sir Keith Joseph (Secretary of State for Education and Science). Sir Keith is still awaiting news from the Kendrew committee on Britain's future role in highenergy physics, so the physicists' intervention is opportune. Friction between highenergy physicists and others supported by SERC, which pays the annual subscription to CERN (the European Organisation for Nuclear Research), is exacerbated by the fluctuating cost of the subscription in pounds sterling against what is now a constant subscription in Swiss francs, and any realistic way of handling the fluctuations would at least ease tempers.

According to Perkins and Mulvey, the issue is this. Member states of CERN pay their subscriptions in Swiss francs according to their "net national income" (NNI) averaged over three years. The proportions are determined every three years using the most recent statistics of the United Nations Statistical Office. But these statistics can be three years old, with the result that actual payments can be six years out of line with real current NNI. "For example, the present shares were decided in 1983, using data for 1979-81. They will be in force for 1984-86."

Nevertheless, in the long run, exchange rate fluctuations are automatically corrected, as NNIs are calculated in dollars. So if sterling falls the British NNI falls with it. But the delay in calculations causes trouble. Recently, the sterling cost of the CERN subscriptions has risen sharply from $£ 23$ million in 1981 to $£ 35$ million in 1984 because sterling, and hence NNI, was strong against the dollar in 1979-81 but has fallen nearly twofold since.

According to Perkins' and Mulvey's calculations, the net overspend (out-turn minus estimate) by SERC on the CERN subscription over the eleven years starting 1971-72 was only $£ 4.75$ million (just over one per cent of the total). From year to year, however, the overspend has been as high as $£ 4.5$ million (1976-77) and as low as minus $£ 8.7$ million $(1980-81)-$ a profit for SERC.

"Exchange rate and relative NNI changes are quite outside the control of anyone", write Perkins and Mulvey, "and the application of 'cash limits' (inclusive of the international subscriptions) to the already desperately strained SERC budget does not encourage economy. It only sub- jects the scientific programmes to arbitrary jolts which have very damaging, and wasteful, effects."

Thus they recommend:

- That subscriptions to international research organizations (such as CERN) should remain part of the budget of the appropriate scientific policy-making body (for example SERC). "Then the trend of the budget . . . can be decided in the right scientific context."

- That the delay in the calculation of relative contributions be shortened, "though this may not be welcomed by countries with more stable currencies".

- That SERC could pay foreseen subscriptions in sterling, while the Treasury corrects for changes in the exchange rate and NNI by adding or subtracting the appropriate sums. "This separates the functions of making scientific policy (SERC) and solving the technical problems (Treasury).... Experience shows that the Treasury (and SERC) would not lose (or gain) over a number of years."

Moreover, Perkins and Mulvey claim, "there can be no objection in principle to such a mechanism since cash limits are not applied to the international payments made by the Foreign and Commonwealth Office".

Here, however, there appears to be some uncertainty. According to a Treasury spokesman, Foreign and Commonwealth Office (FCO) international subscriptions (to the United Nations, for example) are indeed not cash limited, which means that the Treasury will bail out FCO if there are political changes in those subscriptions during a financial year, but on currency fluctuations, FCO must look for "offsetting savings", according to the Treasury. However, unlike SERC, FCO has a longstanding "arrangement" with the Treasury by which the fluctuations are discussed as they occur.

Robert Walgate

\section{NSF deputy at last}

DR John H. Moore, an economist at the Hoover Institution in Stanford, California, has been nominated by President Reagan to be deputy director of the National Science Foundation (NSF), a post that has been vacant for two years.

Although Dr Moore has an undergraduate degree in chemical engineering and worked as an industrial research chemist for four years, his PhD is in economics, a subject to which he has devoted the bulk of his professional career.

Moore has been a member of the National Science Board, NSF's formal governing body, for the past two years.

The Hoover Institution is a generally conservative think-tank associated with Stanford University.

\section{Archaeopteryx Fraudulent feathers?}

SCIENTISTS at the British Museum (Natural History) met on Monday to launch their response to the mounting publicity surrounding the claim by Lee Spetner in Rehovot and a group including Fred Hoyle and Chandra Wickramasinghe from University College Cardiff, that the feather impressions on their specimen of the famous fossil bird-like reptile Archaeopteryx may be a fake.

The controversial claim has been raised by an editorial and an article accompanying new photographs of this specimen published by the group in the British Journal of Photography two weeks ago. The crux of the claim is that many of the feather impressions occur on patches of material that are much finer-grained than the underlying rock and in parts the material looks like "flattened blobs of chewing gum". The possibility is that this represents some sort of cement that was applied to the fossil after discovery, on which feather impressions were made.

To elevate the argument from rhetoric and refutation, the scientists at the museum decided at their meeting to carry out two tests on the fossil specifically to address the possible existence of a cement layer. They will first take a section of material from the edge of the specimen for standard microscopic sedimentational analysis to detect any differences in particle size and the existence of a boundary between a surface layer and underlying material. They will then use electron microprobe analysis to compare X-ray spectra emitted by surface and underlying material.

The team is not, however, optimistic that these tests will provide clear-cut evidence and is already aware that a cement made from underlying rock might not be detected by these analyses. Although ready to carry out these tests immediately, the team feels it may be best if the areas selected for analysis are chosen by Hoyle's group.

The decision to allow samples of material to be taken from this extremely important fossil results from the conviction, voiced by Dr Alan Chong of the Department of the Palaeontology at the museum, that the specimen is genuine. He would seem to have considerable support from the existence of five other specimens assigned to Archaeopteryx from the Upper Jurassic. All have associated feather impressions but were discovered at different times and at different sites. Indeed, the incomplete Tyler specimen discovered in 1855 was first described as a pterodactyl, and it was not until 1972 that John Ostrom noted the feather impressions and described it as Archaeopteryx. If the feather impressions are the work of a single faker, he must have been remarkably fleet of foot and very prescient.

Nigel Williams 